\title{
Attitude towards condom use and HIVIAIDS knowledge as potential determinants of condom use self-efficacy among hispanic youths
}

\author{
E James Essien ${ }^{1,2}$, P Ehsanzadeh-Cheemeh, Emmanuel Monjok ${ }^{1}$, \\ Gbadebo O Ogungbade1, John Balogun², Angela F Meshaek ${ }^{2}$, Doriel Ward ${ }^{2,3}$ \\ and Laurens Holmes jr*1,2,3
}

Address: ${ }^{1}$ HIV Prevention Research Group, College of Pharmacy, University of Houston, 1441 Moursund Street, Houston Texas, 77030, USA, ${ }^{2}$ University of Texas-Houston, School of Public Health, 1200 Herman Pressler, Houston, Texas, 77030, USA and ${ }^{3}$ Department of General Internal Medicine, Anderson Cancer Center, Utah, Maryland, USA

Email: Laurens Holmes* - lholmes3@uh.edu

* Corresponding author

from 2006 International Meeting of The Institute of Human Virology Baltimore, USA. 17-2I November, 2006

Published: 2I December 2006

Retrovirology 2006, 3(SuppI I):P28 doi:I0.I I86/I742-4690-3-SI-P28

(C) 2006 Essien et al; licensee BioMed Central Ltd.

\begin{abstract}
Aims
HIV risk behaviors, modes of transmission and prevention have been described in Hispanic population but there are few studies that address inner city Hispanic youths. We aimed to examine the association between condom use self-efficacy, HIV/AIDS knowledge, as well as attitude towards condom use.
\end{abstract}

\section{Methods}

A cross sectional observational design was used to obtain information on socio-demographics, HIV knowledge, condom use attitude, and condom use self-efficacy in a sample of one hundred inner city Hispanic youths residing in Houston, Texas. A Chi square distribution was used to test the group differences, while logistic regression model was used to assess the association between condom use self-efficacy and the independent covariates.

\section{Results}

In the unadjusted uinvariable logistic regression model, there was a statistically significant association between condom use attitude and condom use self-efficacy, prevalence odds ratio (POR), 6.2, 95\% confidence interval (CI) $=2.4-16.5$. Likewise, there was a statistically significant association between HIV knowledge and condom use selfefficacy, POR, 3.4; 95\% CI $=1.5-8.2$. In the adjusted model, there was a statistically significant association between condom use attitude and condom use self-efficacy, adjusted prevalence odds ratio (APOR), 3.2, 95\%; CI $=1.2-8.5$. However there was no statistically significant association between HIV knowledge and condom use selfefficacy, $\mathrm{p}>0.05$.

\section{Conclusion}

In this sample of Hispanic youths, attitude toward condom use enhances condom use self-efficacy, whereas HIV knowledge does not predict condom use self-efficacy. 